Felipe C. M.

Prando

\title{
RELATO SOBRE UNA VISITA A LOS MUSEOS DE RÍO DE JANEIRO
}

El último día de la visita a Río de Janeiro, el 26 de octubre del 2013, quienes asistieron al debate "Desafíos para el Museo de Arte de Río de Janeiro", celebrado en el Museo de Arte de Río (MAR), se vieron sorprendidos por el ruido de varias explosiones. El panel del debate estaba conformado por Luiz Guilherme Vergara (Museo de Arte Contemporáneo de Niteroi - MAC-Niteroi), Luís Camilo Osório (Museo de Arte Moderno do Río de Janeiro - MAM-RJ), Eugenio Valdés Figueroa (Casa Daros) y Paulo Herkenhoff (MAR), con Martin Grossmann (Fórum Permanente) como facilitador. De inmediato, el director general del MAR, Paulo Herkenhoff, explicó que las dos o tres detonaciones habían sido implosiones para la construcción de un túnel como parte del nuevo complejo vial de la zona portuaria de Río de Janeiro. Las mismas constituyeron una señal clara de un proceso de transformación que afecta a los Museos de arte de manera directa o indirecta.

\footnotetext{
${ }^{1}$ Las grabaciones de este debate y de otras actividades de las visitas a las instituciones artísticas y culturales de la ciudad de Río de Janeiro realizadas entre los días 21 y 26 de octubre de 2013 pueden ser consultadas en la plataforma Fórum Permanente en: http://www.forumpermanente.org/event_pres/cursos-disciplinas/o-lugar-a-funcaoe-o-uso-da-arte-contemporanea/calendario_2013.
} 
En las últimas décadas del siglo XX, el periodista Zuenir Ventura (1994) describió a Río de Janeiro como una "Ciudad Partida", una ciudad dividida entre la sociedad civil y los delincuentes. Pese a que existen varias opiniones contrarias a dicho concepto de Ciudad Partida, dado que se da una interacción económica y cultural entre los cerros de las favelas y el asfalto, los pobres y los ricos, los narcotraficantes y el Estado, es innegable que el territorio geopolítico de la ciudad se define por la tensión entre los distintos grupos sociales que lo componen.

Hoy en día, mediante campañas de pacificación ${ }^{2}$-militares, urbanísticas y mercadológicas-, se ha producido un falso movimiento de cambio de dicha geopolítica. Uno de sus objetivos es preparar a la ciudad para ser anfitriona de los mega eventos deportivos del 2014 (Campeonato Mundial FIFA) y 2016 (Juegos Olímpicos). Río de Janeiro, la ciudad brasileña con mayor influjo de turismo nacional e internacional, es un escenario perfecto para tales eventos del capital global. Sin embargo, la preparación de la ciudad para estos mega eventos ha sido siempre objeto de críticas de parte de numerosas personas que preguntan para quién se está construyendo la ciudad.

\footnotetext{
${ }^{2}$ Las Unidades de Policía Pacificadora (UPP) son oficialmente descriptas como una política de seguridad pública basada en una patrulla comunitaria aliada al fortalecimiento de políticas sociales. En realidad, se trata de una ocupación militarizada de un territorio controlado por el narcotráfico. Tras algunos años de funcionamiento, las críticas a la ausencia de las políticas sociales y denuncias de abusos de poder cometidos por policiales son cada vez más frecuentes. Un caso que tomó grandes repercusiones fue el desaparecimiento del albañil Amarildo, que, tras ser detenido por policiales militares en la puerta de su casa y conducido a una UPP en la favela de Rocinha, nunca más apareció. Sobre las UPP, consultar: Teixeira, E. T. (2010) Unidades de Policía Pacificadora: o que são, a que anseios respondem e quais desafios colocam aos ativismos urbanos? - 1a Parte. Recuperado en 10 de junio 2015 de http://passapalavra.info/2010/06/25554. Caso Amarildo (2015). En Wikipedia. Recuperado en 10 de junio de 2015 de https://pt.wikipedia.org/wiki/Caso_Amarildo. Unidade de Polícia Pacificadora. En UPPRJ. Recuperado en 10 de junio de 2015 de http://www.uppj.com/
} 
Además de las explosiones que marcaron el último día de la visita a Río, el primer día (21/10/2013) coincidió con la subasta de "Campo de Libra", parte del primer lote de explotación petrolera del Presal, que convertirá a Brasil en uno de los principales productores mundiales de petróleo ${ }^{3}$. Gracias al Presal, las reservas brasileñas de petróleo saltarán de 14.200 millones de barriles a 74.000 millones, con lo que el país se haría autosuficiente por 60 años. En ese momento, cuando aún se respiraban los aires de las manifestaciones de junio, la ciudad se encontraba bajo vigilancia militar.

En junio del 2013, la ciudad de Río de Janeiro, al igual que muchas ciudades brasileñas, fue avasallada por una serie de manifestaciones que congregaron a cientos de miles de personas en las calles. Dichas manifestaciones comenzaron en la ciudad de Sao Paulo, cuando el Movimiento por el Pase Libre (MPL) convocó a varias protestas en pos de la reducción de las tarifas de transporte público. Como consecuencia, se generó un debate sobre la relación entre la ciudad y sus habitantes basada en su capacidad o incapacidad de trasladarse de un lugar a otro. Una semana después, las manifestaciones se propagaron a otras ciudades y la lista de reivindicaciones se extendió a temas como el combate a la corrupción y el mejoramiento de los servicios públicos, además de criticar el sistema de representación política.

Las manifestaciones de junio del 2013 y la licitación de Campo Libra tuvieron como trasfondo una serie de cambios experimentados por la sociedad brasileña en los últimos 15 años, cuyo resultado fue un nuevo estrato social que Jessé de Souza denominó "los luchadores"

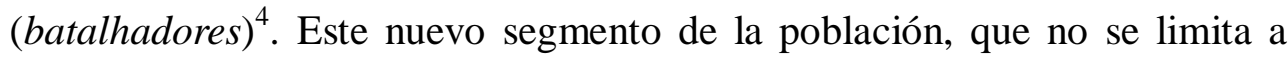

${ }_{3}^{3}$ CARDoSo, J. A., e MINEIRO, A. (2013). Observaciones sobre o leilão do Campo de Libra. Em Brasil de Fato, recuperado em 10 de junho de 2015, de http://www.brasildefato.com.br/node/26356.

${ }^{4}$ SOUZA, J. (2010). Os batalhadores brasileiros: nova classe média ou nova classe 
una nueva categoría económica, de ingreso o de consumo, representa también una nueva estética y un nuevo estilo de vida. En la nueva pirámide socioeconómica brasileña, los luchadores ocupan el espacio entre los pobres, improductivos y sin futuro, y la tradicional clase media brasileña, blanca e ilustrada. Si bien tanto los luchadores como la clase media se encuentran entre los ricos y los pobres, ambos grupos se diferencian debido a la gran precarización del primero.

Dichas transformaciones son el resultado de un proceso de desarrollo que André Singer denominó lulismo en alusión a las políticas económicas y sociales implantadas por el Gobierno Lula entre el 2003 y el $2010^{5}$. Para Singer, quien se desempeñó como vocero de dicho Gobierno del 2003 al 2006, el lulismo instauró una combinación de políticas macroeconómicas conservadoras para el control de la inflación con metas elevadas para el superávit primario, aunadas a políticas microeconómicas de combate a la pobreza extrema, como, por ejemplo, el programa Bolsa-Família (Beca Familiar) y los microcréditos, capaces de activar el mercado interno con la incorporación de los más pobres como consumidores. Es en este contexto político y cultural, donde Brasil y la ciudad de Río de Janeiro reivindican un protagonismo a nivel global, que debemos comprender el papel de las instituciones artísticas y culturales, que se inscriben de maneras diversas en un territorio en permanente reorganización.

A partir del objetivo propuesto por el curso "El lugar, el uso y la función del Arte Contemporáneo", "Analizar y discutir críticamente los contextos de creación, exposición, mediación e institucionalización relativos al sistema actual del arte y de la cultura tomando como contrapunto situaciones específicas", el presente texto se propone comprender, a través del relato,

trabalhadora? Belo Horizonte: UFMG.

${ }^{5}$ SINGER, A. (2012). Os sentidos do lulismo: reforma gradual e pacto conservador. São Paulo: Cia. das Letras. 
el proceder de determinadas instituciones visitadas entre el 21 y el 26 de octubre del 2013.

El Museo de Arte de Río, MAR, nos dio acogida en la ciudad de Río de Janeiro y actuó como punto de referencia e inflexión para la reflexión que aquí se ofrece. Todos los días, después de visitar las instituciones artísticas y culturales, regresábamos al MAR donde un integrante del equipo de curaduría $^{6}$ nos presentaba trabajos que estaban realizando. En nuestras visitas a otras instituciones ${ }^{7}$, se sostuvieron conversaciones bastante informales sobre la historia, programas y perspectivas de cada una de ellas.

\section{Día 22 de octubre del 2013: Visita al Museo de Arte de Río (MAR)}

El paisaje cultural de la ciudad de Río de Janeiro ha marcado profundamente la construcción de su representación social desde la llegada de la Familia Real portuguesa en 1808. La exposición ImagináRio, ubicada en el espacio del MAR dedicado de forma permanente a exposiciones sobre Río de Janeiro, evidencia la construcción cultural de un paisaje que convierte a los sujetos sociales en actores secundarios en un territorio construido por ellos. El predominio del paisaje concebido como naturaleza-

${ }^{6}$ Los miembros del equipo de curadoría del MAR que presentaron algunas propuestas del museo fueron el director general, Paulo Herkenhoff, la gerente de Contenido y Curaduría, Clarissa Diniz, y la gerente de Educación, Janaína Mello.

${ }^{7}$ En el Museo de Arte Contemporáneo de Niterói (MAC-Niterói), fuimos recibidos por Luiz Carlos Vergara, director general-curador; en el Museo de Arte Moderno de Río de Janeiro (MAM-RJ), por Marta Mestre, curadora asistente; en la Casa Daros - Daros Latinoamérica, por Eugenio Valdés Figueroa, curador de Arte y Educación; en la entidad Redes de Desarrollo de Maré, por la artista Lia Figueredo. También fueron visitados el Conjunto Habitacional del Pedregulho, proyectado por el arquitecto Eduardo Reydi, en el cual fuimos recibidos por el líder comunitario Hamilton Marinho; y el Centro Cultural Paço Imperial, en el cual fuimos recibidos por educadores que hacían las visitas guiadas de las exposiciones. 
exuberancia es algo que no solo los primeros extranjeros instituyeron, sino que se extiende a artistas y curadores contemporáneos. En el 2014, el MAR, como parte de su propuesta de ofrecer un Museo local, inaugurará una exposición titulada Do Valongo à favela (De Valongo al tugurio), dado que, según dijo Clarissa Diniz a quienes visitaron la exposición Rio de Imagens (Río de Imágenes), una de las muestras inaugurales del Museo, la presencia del negro no era tan contundente ${ }^{8}$. Es muy probable que la construcción de la representación social de la ciudad de Río de Janeiro se pueda narrar mediante la producción de invisibilidades. Para hacer valer el imaginario, ¿qué invisibilidades se producen?

La creación del MAR, inaugurado en marzo del 2013, se dio como parte del Projeto Porto Maravilha (Proyecto Puerto Maravilloso). Presentado como un proyecto de gran impacto cultural, el Museo es una de las intervenciones urbanísticas descritas como una operación urbana con miras a preparar la zona portuaria de la ciudad para integrar un proceso de desarrollo económico marcado por los grandes eventos de que será sede la ciudad. En realidad, Porto Maravilha se manifiesta como una práctica de la revitalización urbana según la lógica de la privatización del espacio público, así como la gentrificación de la zona portuaria de Río de Janeiro. La primera ola de reurbanización y gentrificación de la plaza Mauá, donde se encuentra el MAR, se dio con la Reforma Urbana impulsada por el alcalde Pereira Passos (1903-6), quien se propuso darle a Río de Janeiro aires de una ciudad burguesa europea mediante la construcción de un inmenso bulevar que surcaba el centro de la ciudad. Así, se le ofrecía a una ciudad con un pasado colonial-imperial la experiencia de la modernidad.

El proyecto Porto Maravilha contempla, además del Museo y de las futuras torres empresariales de Donald Trump, diversas expropiaciones en la favela

${ }^{8}$ DINIZ, C. (2013, 22 de octubre). Sem título. Apresentación. Museu de Arte do Rio. 
Morro da Providência. El artista Yuri Firmeza utilizó escombros de las edificaciones demolidas para crear una parte de su exposición Yuri Firmeza: turvações estratégicas, presentada en el MAR. Los escombros de Morro da Providência se ubicaron cerca de las piezas arqueológicas halladas durante la remodelación del edificio que alberga al Museo. Lo anterior constituye un intento de parte del artista y de la curaduría del MAR de abordar las invisibilidades generadas por Porto Maravilha, que, al actuar en un plano simbólico, termina por ofrecernos una especie de monumento a la memoria o al olvido.

\section{Día 25 de octubre del 2013: Visita a la institución Redes de Desenvolvimento da Maré (Redes da Maré)}

El Complexo da Maré es uno de los conglomerados de favelas más grandes de Río de Janeiro, donde habitan 130 mil personas en 16 comunidades (barrios) que se extienden entre dos de las vías de acceso principales de la ciudad de Río de Janeiro. Dichas comunidades, organizadas mediante Redes da Maré, desarrollan proyectos tendientes a efectuar cambios a escala local, tanto simbólicos como reales. El primer proyecto de Redes da Maré surgió por iniciativa de los residentes y ex residentes que llegaron a la universidad y constataron que menos del 1\% de la población de Maré había accedido a la educación superior ${ }^{9}$. Al cabo de 13 años de trabajo, el 1,8\% de la población de Maré, más de 1.000 personas, ha tenido acceso a la educación superior. En promedio, 80 alumnos del curso preparatorio aprueban el examen de ingreso a diversas universidades de Río de Janeiro anualmente.

Otro proyecto también constituido a partir de puntos de invisibilidad es el

${ }^{9}$ Rede de Saberes: preparando o futuro dos jovens da Maré. (2011). Redes da Maré. Recuperado em 15 de novembro de 2013, de http://redesdamare.org.br/?p=1418. 
del Censo de Maré. Hasta la década de 1980, las favelas de Río de Janeiro se representaban en los mapas como manchas blancas -una forma de ocultarlas. Actualmente, en Río de Janeiro hay más de 1.000 favelas. El Censo de Maré, al registrar calle por calle, casa por casa, familia por familia, incorporó las favelas del Complexo da Maré al mapa de la ciudad. Los proyectos impulsados por Redes da Maré son estructurantes y no meramente puntuales $\mathrm{u}$ ocasionales, dado que hacerse visible es una condición para existir y pertenecer a la ciudad.

La visita al Complexo da Maré se inició en el Centro de Artes da Maré, producto de una alianza entre la artista Lia Rodrigues, Lia Rodrigues Companhia de Danças y Redes da Maré, para la creación, formación y difusión de las artes, con especial énfasis en la danza contemporánea. Al igual que otros proyectos existentes en Maré, este proyecto, desarrollado por la artista Lia Rodrigues, entabla relaciones con personas, no con las cifras que son importantes para algunos informes anuales. En un área tan extensa, la participación de la gente en los proyectos se da en una escala de 1:1; es local e individualizada.

Las experiencias de Redes da Maré y del Centro de Artes da Maré las caracterizan como instancias de mediación en el sentido propuesto por Gilberto Velho, pues “[...] tienden puentes entre diferentes, reinventan códigos, redes de significados y relaciones sociales, importantes para la expansión y el desarrollo de una concepción de ciudadanía nueva y más compleja" ${ }^{\prime 10}$. Son experiencias que desencadenan, en los mapas y en las universidades, el contacto entre grupos sociales que por muchos años

10 VELHO, G. (2010). Metrópole, cosmopolitismo e mediación. Horizontes Antropológicos, Porto Alegre, vol. 16, n. 33, jun/2010. Disponível em: http://www.scielo.br/scielo.php?pid=S0104-

$71832010000100002 \&$ script=sci_arttext. Acessado em 20 de novembro de 2013. 
vivieron separados por muros invisibles, si bien no todos los muros son invisibles.

Las favelas y sus habitantes, que por medio de estereotipos y estigmas se hicieron invisibles en la construcción del imaginario de Río de Janeiro, son "blancos" de programas educativos de los Museos ubicados en la ciudad. Año tras año, las instituciones artísticas incrementan sus presupuestos y sus equipos de trabajo en este campo con el fin de fomentar un mayor número de visitas y, en algunas instancias, validar el trabajo con los visitantes. Este movimiento puede entenderse como un esfuerzo por democratizar el Museo, a semejanza de lo que ocurre en otros Museos del mundo. No obstante, según Zdenka Badovinac, es importante recordar que existen diferencias entre el Museo crítico, que se opone a la mercantilización y homogenización de las distintas esferas de la vida social, y el Museo convencional, que desarrolla programas institucionales para atraer a tantos consumidores como sea posible ${ }^{11}$. Esta propuesta de Museo para atraer a la mayor cantidad de consumidores que se pueda se conoce también como Museo blockbuster. En este sentido, se puede comprender la intensión del MAR al definirse como una "escuela con un Museo y, a la vez, un Museo con una escuela". El Museo desarrolla proyectos de curaduría basados en su contexto cultural, alejándose de la concepción de blockbuster. Sin embargo, su concepto de democracia es bastante limitado. En su programa de gestión, el MAR afirma que la democracia es uno de sus valores y la define como "mantener una escucha activa de la sociedad".

¿Qué posibilidades reales tiene un proyecto educativo basado en tal concepción de la democracia de ser emancipador? El Museo mismo establece como su misión “[...] transformar las relaciones de Río con el arte

11 BADOVINAC, Z. (2012, Fall). New forms in cultural production. The Art East Quarterly. Fall 2012. Recuperado em 3 dezembro de 2013, de http://www.arteeast.org/2013/06/29/new-forms-in-cultural-production/. 
en un proceso de formación emancipadora de la ciudadanía". Empero, para Paulo Freire ${ }^{12}$, la capacidad emancipadora de la educación pasaría por la superación de la "educación bancaria", que, traspuesta al contexto del Museo, podría describirse de la siguiente manera: una situación en que el Museo detenta el conocimiento y, sus visitantes, a quienes se narran los resultados de su investigación, quedan en una posición de meros espectadores del mundo. Superar la educación bancaria significa además superar una concepción de la política representativa como la que se enuncia en el concepto de democracia del MAR y avanzar hacia procesos participativos en que los visitantes tengan voz y poder de decisión.

Día 24 de octubre del 2013: Visita al Museo de Arte Moderno de Río de Janeiro (MAM-RJ)

El MAM-RJ cuenta con una trayectoria peculiar en lo que respecta a la relación entre el arte y la educación. Ya en los años 1950-60, el sector educativo del Museo adoptó como una de sus principales características la presencia y cercanía del artista. Por el que entonces era el Sector de Cursos, pasaron Ivan Serpa, Almir Malvigner y Frederico de Morais. Los dos primeros fueron responsables por la formación de toda una generación de artistas concretos y neoconcretos, así como por proyectos revolucionarios, como la alianza con Nise da Silveira, que posibilitó trabajar con internos de un hospital siquiátrico. Por su parte, Frederico de Morais, como crítico de arte, lideró el Sector de Cursos y estuvo a cargo de proyectos como Domingos da Criação (Domingos de Creación) y Arte no Aterro (Arte en el Parque), cuando Hélio Oiticica encargó la Apocalipopótese, en que participaron Antônio Manuel y Lígia Pape. Hasta 1978, el MAM-RJ,

${ }^{12}$ FREIRE, P. (1983). Pedagogia do oprimido, Rio de Janeiro: Paz e Terra. 
siempre con la presencia del artista, impulsado por su proyecto arquitectónico y por la búsqueda de la comprensión del arte por parte de sus visitantes, existió "fuera de sí mismo", desacralizando el arte y vertiendo la creatividad de los artistas en las calles ${ }^{13}$.

El MAM-RJ, creado entre los años 1940-50, atraviesa una situación de "precariedad institucional" reflejada en muchas instituciones artísticoculturales brasileñas. Su modelo institucional se inspiró en el MoMA-NY, dirigido en ese entonces por Nelson Rockfeller, de quien el MAM-RJ recibió en su fundación una importante donación de obras de arte moderno. Se trata de un modelo que depende de la cercanía y compromiso de una élite responsable por el financiamiento de la institución. Dicho mecenazgo basado en donaciones de dinero y obras de arte sería de carácter privado. Sin embargo, hoy en día, el Museo se financia casi en su totalidad por medios públicos, mediante las exenciones fiscales otorgadas por las Leyes de Incentivo a la Cultura. Dicho mecanismo de financiamiento de proyectos culturales obliga al Museo a crear proyectos, aprobar y captar fondos para cada exposición, todo lo cual debe hacerse a través de asociaciones de amigos del Museo para que se pueda tener acceso a tales recursos. Así, el programa institucional se limita a proyectos que generen visibilidad y publicidad para las empresas. Según Marta Mestre ${ }^{14}$, curadora asistente del MAM-RJ, en ocasiones el Museo ha expuesto proyectos que recibió listos, en cuya elaboración el Museo no participó. Actualmente, según la misma curadora, se hace todo lo posible para evitar que tales situaciones se repitan.

El 8 de julio de 1978, un incendio destruyó el 80\% de su acervo, además de una retrospectiva del artista uruguayo Joaquín Torres García. Hoy, el MAM-

13 RIBEIRO, M. A. (2013) Entrevista com Frederico Morais. Rev. UFMG, Belo Horizonte, v. 20, n.1, jan/jun, p. 342. Disponible en:

https://www.ufmg.br/revistaufmg/downloads/20/18-entrevista_fredrico_morais.pdf. 14 MESTRE, M. (2013, 23 de octubre). Sem título. Apresentación. Museu de Arte Moderna do Rio de Janeiro. 
RJ cuenta con un acervo de aproximadamente 16.000 obras, el $50 \%$ de las cuales corresponde a dos colecciones privadas (Gilberto Chateaubriand y Joaquim Paiva) cedidas al Museo en régimen de comodato. En otras palabras, las obras les pertenecen a los coleccionistas y se encuentran en el Museo en calidad de préstamo por un tiempo determinado.

El MAM-RJ, proyectado por el arquitecto Eduardo Afonso Reidy, forma parte de un proyecto modernista que buscó, por un lado, la internacionalización y, por otro, la construcción de una cultura nacional. En los años 1940-50, Río de Janeiro se vio marcado por el surgimiento de verdaderos monumentos de la arquitectura modernista brasileña, como el edificio del Ministerio de Educación y Cultura (Palacio Gustavo Capanema), el parque Aterro do Flamengo, el complejo residencial de Pedregulho, el Parque Guinle y otras obras alineadas con los preceptos propuestos en los Congresos Internacionales de Arquitectura (CIAM).

\section{Día 22 de octubre del 2013: Visita al Museo de Arte Contemporáneo de Niteroi (MAC- Niteroi)}

En el MAC-Niteroi, inaugurado en 1996, presenciamos la utilización del Museo como estrategia para incorporar a una ciudad al mapa cultural contemporáneo. Este Museo, encargado al arquitecto Oscar Niemeyer, se construyó para recibir en comodato 1.217 obras de arte moderno y contemporáneo de la colección privada "João Sattamini”. Según su director general, Luiz Guilherme Vergara, docente de la Universidad Federal Fluminense, en el 2013, el MAC-Niteroi llevaba una línea de investigación 
de trabajos hechos por artistas-investigadores para el acervo de la Colección MAC de Niteroi ${ }^{15}$.

La construcción del MAC-Niteroi corresponde más a la lógica de un monumento que de un Museo propiamente dicho. Los encargados de la construcción del Museo lo pensaron como un cascarón, un envoltorio, sin tomar en cuenta su contenido, la necesidad de programación y de recursos para su mantenimiento. Desde un principio, pese a los reiterados recortes presupuestarios, los equipos de curaduría se afanaron por desarrollar un programa institucional. Sin embargo, los retos económicos son numerosos. El día de nuestra visita, el Museo se encontraba cerrado al público por problemas de infraestructura.

\section{Día 24 de octubre del 2013: Visita a la Casa Daros}

La infraestructura no es problema en la Casa $\operatorname{Daros}^{16}$, que recibió una inversión de US\$30 millones destinados a la compra y remodelación del inmueble sede de esta institución. Su inauguración, en el 2013, fue producto de 10 años de planificación. La exposición inaugural, "Cantos Cuentos Colombianos", contó con obras de diez artistas contemporáneos colombianos.

La Casa, concebida como un espacio de arte, educación y comunicación, pertenece a Daros Latinoamérica, cuya sede se encuentra en Zúrich, Suiza. Desde sus inicios, en 1999, la colección ha tenido como curador a HanzMichel Herzog. Las más de 1.200 obras de arte contemporáneo

15 VERGARA, L. G. (2013, 22 de octubre). Sem título. Apresentación. Museu de Arte Contemporânea de Niterói.

${ }^{16}$ Sobre la instalación y el cierre de las actividades de la Casa Daros en la ciudad de Río de Janeiro, es posible consultar el Dossier Casa Daros publicado por el Fórum Permanente en http://www.forumpermanente.org/imprensa/daros. 
latinoamericano son de propiedad de la coleccionista suiza Ruth Schmidheiny, ex esposa de Stephan Schmidheiny, un empresario de la industria del cemento y amianto.

Según Eugenio Valdés Figueroa, curador de Arte y Educación, la Casa Daros, con su vocación internacional, tiene a la educación como eje fundamental de trabajo. Refiriéndose varias veces al pensador brasileño Paulo Freire, el curador aseveró que el proceso creativo de los artistas es una estrategia pedagógica explorada en algunos de sus más de nueve proyectos educativos.

En mayo del 2015, al cabo de diez años de planificación, dos años de funcionamiento y con inversiones por más de US\$30 millones, la Casa Daros comunicó sin muchas explicaciones que, en diciembre del 2015, cerrará sus puertas.

\section{Consideraciones}

En las décadas de 1990 y 2000, presenciamos el surgimiento de una nueva estructura económica en la que la organización de la actividad productiva cambió drásticamente para trascender la búsqueda de mercados globales, dado que la producción misma pasó a ser de índole global. En este nuevo escenario, también las ciudades sufrieron transformaciones con el fin de atraer inversiones financieras. En lugar de equipamientos culturales coloniales como el Teatro Municipal o Museos insertos en un proyecto de cultura nacional, los nuevos equipamientos están llamados a adecuarse a una demanda por lo global. Los años 1990 vieron el boom de las Bienales y Trienales de Arte y el caso del Museo Guggenheim Bilbao. Este Museo, inaugurado en 1997, se convirtió en un símbolo arquitectónico de la 
globalización por tratarse de una intervención urbana especializada en construir lugares capaces de ejercer un poder de atracción significativo sobre los flujos de capital. La construcción del Museo convirtió a la capital vasca en una atracción turística mundial. Desde entonces, se vive el "efecto Bilbao", gracias al cual “[...] cada ciudad busca construir un espectáculo de magnitud similar con el objetivo de atraer nuevos flujos de capital"17.

El lugar que ocupa hoy el MAR, decisión que, según Paulo Herkenhoff ${ }^{18}$, es expresión de un deseo personal del alcalde Eduardo Paes, habría sido la ubicación del Guggenheim Río de Janeiro ${ }^{19}$, si el ex alcalde César Maia hubiese logrado su cometido. La propuesta del ex alcalde, presentada en el 2005, también apuntaba a revitalizar la zona portuaria. Si bien el MAR no ocupa exactamente el lugar físico destinado al Guggenheim, que se habría construido en el muelle Mauá, debido a su papel en el proyecto Porto Maravilha, se puede afirmar que ocupa su lugar simbólico.

Por su parte, el periódico Maré de Notícias, un proyecto de comunicación de Redes da Maré, dice lo siguiente en su número de octubre del 2013:

\begin{abstract}
Hablando de obras, en setiembre, el alcalde anunció a los líderes comunitarios el lanzamiento del programa Bairro Maravilha (Barrio Maravilloso) aquí, en Maré (véase págs. 8 y 9). Eduardo Paes habló de inversiones por hasta $\mathrm{R} \$ 400$ millones mediante una emisión de títulos. Decidimos divulgar este tema con cautela. Por ahora, no recurriremos a titulares. De hecho, aún no sabemos qué intervenciones habrá ni si la alcaldía tiene previsto algún proceso de participación de los vecinos.
\end{abstract}

¡Estaremos atentos!

¡Deseamos a todos y todas que disfruten de esta edición!

17 ARANTES, P. F. (2010). A renda da forma na arquitetura da era financeira. In: OLIVEIRA, Francisco (Org.) Hegemonia às avessas: economia, política e cultura na era da servidão financeira. São Paulo: Boitempo, p. 174

18 HERKENHOFF, P. (2013, 26 de octubre). Sem título. Apresentación. Museu de Arte do Rio.

${ }^{19}$ Sobre el proyecto de construcción de un Museo Guggenheim en la ciudad de Río de Janeiro, es posible consultar el Dossier Polêmica Guggenheim publicado por el Fórum Permanente en http://www.forumpermanente.org/imprensa/polemica_gugg. 


\section{REFERENCIAS}

ARANTES, P. F. (2010). A renda da forma na arquitetura da era financeira. In: OLIVEIRA, Francisco (Org.) Hegemonia às avessas: economia, política e cultura na era da servidão financeira. São Paulo: Boitempo.

BADOVINAC, Z. (2012, Fall). New forms in cultural production. The Art East Quarterly. Fall 2012. Obtenido el 3 de diciembre del 2013. http://www.arteeast.org/2013/06/29/new-forms-in-cultural-production/.

CARDOSO, J. A., y MINEIRO, A. (2013). Observações sobre o leilão do Campo de Libra. Brasil de Fato. Obtenido el 10 de junio del 2015. http://www.brasildefato.com.br/node/26356.

CASO AMARILDO. (2015). Wikipedia. Obtenido el 10 de junio del 2015. https://pt.wikipedia.org/wiki/Caso_Amarildo.

DINIZ, C. (2013, 22 de octubre). Sin título. Presentación. Museo de Arte de Río. Rede de Saberes: preparando o futuro dos jovens da Maré. (2011). Redes da Maré. Obtenido el 15 de noviembre del 2013. http://redesdamare.org.br/?p=1418.

FREIRE, P. (1983). Pedagogia do oprimido, Rio de Janeiro: Paz e Terra.

HERKENHOFF, P. (2013, 26 de octubre). Sem título. Apresentación. Museu de Arte do Rio.

MESTRE, M. (2013, 23 de octubre). Sin título. Presentación. Museo de Arte Moderno de Río de Janeiro.

RIBEIRO, M. A. (2013) Entrevista com Frederico Morais. Rev. UFMG, 
Belo Horizonte, v. 20, n.1, jan/jun, p. 336-351. https://www.ufmg.br/revistaufmg/downloads/20/18entrevista_fredrico_morais.pdf.

SINGER, A. (2012). Os sentidos do lulismo: reforma gradual e pacto conservador. São Paulo: Cia. das Letras.

SOUZA, J. (2010). Os batalhadores brasileiros: nova classe média ou nova classe trabalhadora? Belo Horizonte: UFMG.

TEIXEIRA, E. T. (2010) Unidades de Polícia Pacificadora: o que são, a que anseios respondem e quais desafios colocam aos ativismos urbanos? $-1^{\text {a }}$ Parte. Obtenido el 10 de junio del 2015. http://passapalavra.info/2010/06/25554.

UNIDADE DE POLÍCIA PACIFICADORA. (2015). UPPRJ. Obtenido el 10 de junio del 2015. http://www.upprj.com/.

VELHO, G. (2010). Metrópole, cosmopolitismo e mediação. Horizontes Antropológicos, Porto Alegre, vol. 16, n. 33, jun/2010. http://www.scielo.br/scielo.php?pid=S0104$71832010000100002 \&$ script=sci_arttext. Obtenido el 20 de noviembre del 2013 .

VENTURA, Z. (1994). Cidade Partida. São Paulo: Companhia das Letras.

VERGARA, Luiz Guilherme. (2013, 22 de octubre). Sin título. Presentación. Museo de Arte Contemporáneo de Niteroi. 